\title{
The sauropodomorph biostratigraphy of the Elliot Formation of southern Africa: Tracking the evolution of Sauropodomorpha across the Triassic-Jurassic boundary
}

\author{
Blair W. McPhee, Emese M. Bordy, Lara Sciscio, and Jonah N. Choiniere \\ Acta Palaeontologica Polonica 62 (3), 2017: 441-465 doi:https://doi.org/10.4202/app.00377.2017
}

The latest Triassic is notable for coinciding with the dramatic decline of many previously dominant groups, followed by the rapid radiation of Dinosauria in the Early Jurassic. Among the most common terrestrial vertebrates from this time, sauropodomorph dinosaurs provide an important insight into the changing dynamics of the biota across the Triassic-Jurassic boundary. The Elliot Formation of South Africa and Lesotho preserves the richest assemblage of sauropodomorphs known from this age, and is a key index assemblage for biostratigraphic correlations with other similarly-aged global terrestrial deposits. Past assessments of Elliot Formation biostratigraphy were hampered by an overly simplistic biozonation scheme which divided it into a lower "Euskelosaurus

" Range Zone and an upper Massospondylus Range Zone. Here we revise the zonation of the Elliot Formation by: (i) synthesizing the last three decades' worth of fossil discoveries, taxonomic revision, and lithostratigraphic investigation; and (ii) systematically reappraising the stratigraphic provenance of important fossil locations. We then use our revised stratigraphic information in conjunction with phylogenetic character data to assess morphological disparity between Late Triassic and Early Jurassic sauropodomorph taxa. Our results demonstrate that the Early Jurassic upper Elliot Formation is considerably more taxonomically and morphologically diverse than previously thought. In contrast, the sauropodomorph fauna of the Late Triassic lower Elliot Formation remains relatively poorly understood due to the pervasive incompleteness of many key specimens, as well as the relative homogeneity of their diagnostic character suites. Our metrics indicate that both Elliot Formation and global sauropodomorph assemblages had greater morphological disparity within the Early Jurassic than the Late Triassic. This result is discussed in the context of changing palaeoclimatic conditions, as well as macroevolutionary events associated with the end-Triassic extinction.

Key words: Dinosauria, Sauropodomorpha, disparity, Triassic-Jurassic boundary, South Africa.

Blair W. McPhee [blair.mcphee@gmail.com], Departamento de Biologia, FFCLRP, Universidade de São Paulo, Ribeirão Preto, São Paulo, 14040-901, Brazil; and Evolutionary Studies Institute, University of the Witwatersrand, Private Bag 3, Johannesburg, Gauteng, 2050, South Africa. Emese M. Bordy [emese.bordy@uct.ac.za 
] and Lara Sciscio [1ara.sciscio@uct.ac.za], Department of Geological

Sciences, University of Cape Town, Western Cape, 7701, South Africa.

Jonah N. Choiniere [Jonah.Choiniere@wits.ac.za], Evolutionary Studies Institute, University of the Witwatersrand, Private Bag 3, Johannesburg, Gauteng, 2050, South Africa.

This is an open-access article distributed under the terms of the Creative Commons Attribution License (for details please see creativecommons.org), which permits unrestricted use, distribution, and reproduction in any medium, provided the original author and source are credited.

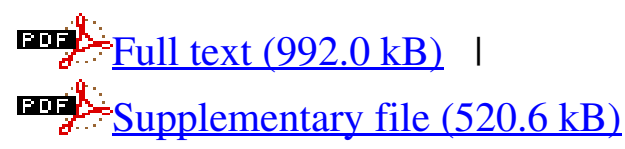

